\title{
Reduced Learning Time with Maintained Learning Outcomes
}

\author{
Olle Bälter \\ ob1@kth.se \\ KTH Royal Institute of Technology \\ Sweden, Sweden
}

\author{
Richard Glassey \\ glassey@kth.se \\ KTH Royal Institute of Technology \\ Stockholm, Sweden
}

\author{
Mattias Wiggberg \\ wiggberg@kth.se \\ KTH Royal Institute of Technology \\ Stockholm, Sweden
}

\begin{abstract}
Many online learning initiatives have failed to reach beyond the environments in which they were first developed. One exception is the Open Learning Initiative (OLI) at Carnegie Mellon University (CMU). In an attempt to validate the question-based learning methodology implemented in OLI, we developed online material for an introductory course in object-oriented programming, and tested it on two course offerings with a total of 70 students. As our course has been given in the same format for several years, we also had comparable assessment data for two classes prior to our intervention in order to determine that we did not introduce any obvious harm with this methodology. Findings show a reduced teaching and learning time by $25 \%$. No statistically significant differences could be found in the results of the assessment quizzes nor confidence surveys completed by the students. The two teachers (the same who handled the classes before the intervention) took different paths to teaching preparations with this new methodology. One teacher increased preparations, whilst the other reduced them, but both teachers were convinced that using online question-based learning was superior to the previous lecture and textbook-based approach, both for the students and themselves in terms of overall satisfaction. We also gathered time logs from the development to estimate return on investment.
\end{abstract}

\section{CCS CONCEPTS}

-Human-centered computing $\rightarrow$ User studies; • Applied computing $\rightarrow$ Computer-assisted instruction; Interactive learning environments; E-learning; Learning management systems.

\section{KEYWORDS}

Question-based learning; Introductory programming; Evaluation

\section{ACM Reference Format:}

Olle Bälter, Richard Glassey, and Mattias Wiggberg. 2021. Reduced Learning Time with Maintained Learning Outcomes. In Proceedings of the 52nd ACM Technical Symposium on Computer Science Education (SIGCSE '21), March 13-20, 2021, Virtual Event, USA. ACM, New York, NY, USA, 6 pages. https: //doi.org/10.1145/3408877.3432382

\section{INTRODUCTION}

In 2008, the Open Learning Initiative (OLI) at Carnegie Mellon University (CMU) showed that a digitally supported Question-Based

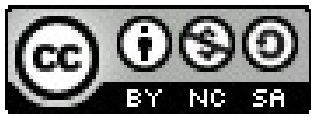

This work is licensed under a Creative Commons Attribution-NonCommercialShareAlike International 4.0 License.

SIGCSE '21, March 13-20, 2021, Virtual Event, USA

(C) 2021 Copyright held by the owner/author(s).

ACM ISBN 978-1-4503-8062-1/21/03.

https://doi.org/10.1145/3408877.3432382
Learning (QBL) methodology could reduce learning and teaching time by $50 \%$ in a university Statistics course, with maintained learning outcomes [23]. The CMU study was done with American students who pay tuition fees for attending CMU. It can be argued that the situation might differ at tuition free universities. Also, their Statistics course has beed developed and refined for over a decade, and some of the effects could possibly be explained by very refined learning material, rather than the actual methodology.

One obstacle for digitalization is the necessary investments needed for the online material - if you strive for high quality, it will be expensive. Estimates are in the area of 100-160hrs to produce one hour of ready online learning content [8]. Another is that the return on investment is unclear. For example, if a teacher spends their "spare" time to record videos to streamline teaching, but the result in the end will be that time allotment for the course is reduced. That is the teacher spends time on streamlining, but the university collects all the gains [15].

The purpose of this study is twofold: RQ1: Can we repeat the "no-harm" parts of the 2008 CMU study? RQ2: Is "good enough" learning material sufficient for achieving some of the positive effects reported by CMU?

We do this by developing an introductory course in objectoriented programming (using Java), in the current version of the $\mathrm{CMU}$ platform. In the CMU study, they reduced learning time by $50 \%$. Since our learning material is untested, we only attempted to reduce the learning time by $25 \%$ (from 23 to 17 days) with the same content and assessment.

\section{BACKGROUND}

Teaching interventions in general have been shown to improve pass rates in programming courses [32]. However, digitally supported learning has for a long time been a hope for improving education or at least making it more affordable, but has often failed to deliver on its promise [16]. In a meta-study only 7 out of 77 studies were found to produce positive effects [3]. Hopes for effectiveness have not been met [7]. The increased student diversity has not been addressed [30]. There are significant barriers to adoption and dissatisfaction with the courseware [20,21]. However, review studies have in general described online learning as being just as efficient as traditional classroom education, and blended learning as an even better option [24] even for community college students [26].

Cost per student analysis in general shows lower costs for using online material, but more importantly this can be done while improving student learning $[5,13]$. Thus, it is possible to both reduce costs and improve quality at the same time, especially for large introductory courses where the return on investment is short $[4,12]$. As expected, the positive impact of digital learning material is greater in courses with over 50 students [13], where the possibilities to have individual time with a teacher are much smaller. 
When comparing learning outcomes, it is important to compare actual outcomes and not only ask students for their perceptions, as it has been shown that these perceptions often are wrong [6]. The students tend to rate the amount of effort on their part rather than the actual learning. Since it requires effort to learn, lectures with a great presenter make the students comfortable and think (wrongly) that they learn things at the same time.

From a student perspective, a qualitative study identifies expectations from students that Information Technology (IT) should assist them with focus on the content, organisation and easy access to learning resources [31]. This is related to Self-Regulated Learning (SRL) strategies such as strategic planning, organisation and help seeking. In a review study of learning analytics dashboards, the use of formative assessment as a means for the SRL strategies reflection and self-evaluation was not so common [14], but the OLI methodology relies upon formative assessment.

\subsection{Question-based learning in the Open Learning Initiative}

In the 2008 CMU-OLI study, students were divided randomly into either the traditional campus course or the OLI version. The OLI version ran over half the semester (compared to the control group's traditional full semester course), weekly contact hours were reduced from four to two, but only the OLI group got access to the OLI online material. The evaluations showed that the OLI students performed as well or better than the control group on the mid-term and the final exam [23]. Similar benefits have been reported from other studies of OLI courses, such as higher completion rates (99\% vs. $41 \%$ ) and learning more material [28], high learning gains [29], and a sixfold learning benefit from the learning activities in OLI compared to reading and watching videos $[18,19]$. The last study included data from 12,500 students in four different courses.

The methodology can shortly be described as:

(1) It has a question-based learning approach where the learning material is organised around formative questions mapped to the learning outcomes.

(2) Answering a formative question results in a reinforcement of either why the selected answer is correct, or if it was incorrect, how to think in order to understand what the correct answer would be.

(3) The data collected when students' are answering questions are used in a machine-learning model to predict students' mastery of the learning outcomes. This mastery prediction is used in a flipped-classroom setting to assist the teachers to focus on the learning outcomes that were difficult to master (instead of the results of individual questions).

(4) The information that the course developers get from the click data when the students are answering questions are used to improve the learning material as the prediction model also indicates which parts of the learning material that is wellfunctioning and which should be targeted for improvement.

This is in line with other proposals on important factors in good learning design, such as [27], three opportunities for using learning analytics in learning design: 1) indicators for evidence-based decisions on learning design (step 4 above), 2) intervening during the run-time of a course (3 above) and 3 ) increasing students learning outcomes and satisfaction $(1+2$ above). It is also aligned with one of the seven principles in [1]: Goal-directed practice coupled with targeted feedback enhances the quality of students' learning.

The two first steps are best illustrated with an example question:

\section{What is the mean value of $5,6,5,5,7,6,13,9$ ?}
a: 5
b: 6
c: 7
d: 8

Depending on the answer from the student, the feedback would be one of the following:

a: Incorrect This is the mode. The mean is the sum of all numbers divided with the count of all numbers.

b: Incorrect This is the median. The mean is the sum of all numbers divided with the count of all numbers.

c: Correct The mean is the sum of all numbers divided is the sum of all numbers divided with the count of all numbers.

d: Incorrect This is the count of all numbers. The mean is the sum of all numbers divided with the count of all numbers.

The third part, the feedback to the course developers, is based on breaking down the Learning Objectives (LO) for the course into testable Skills (a.k.a. Knowledge Components) that are tested through a set of questions similar to the one in the example. In this case the LO is: "Relate measures of center and spread to the shape of the distribution, and choose the appropriate measures in different contexts." And one of the skills needed to master that LO is: "Being able to calculate mean values".

Since these courses are often also offered as Massive Open Online Courses, click data from several thousands of students can be analysed. When answering the first question on a skill, it can be expected that not all students will get it right (if so the question was too simple), nor will all students get it wrong (if so, the question was too difficult). Considering the constructive feedback all students get after answering the first question, if all works as it should, the percentage of students failing the 2nd question on the same skill should be lower. Otherwise, there is something wrong. It could be the learning material, the question, the answering alternatives, the feedback, etc, but the important thing here is that the system gives feedback to the course developers on where something is wrong, so that it can be improved (for a more elaborate explanation on OLI, see [30]; the underlying learning model, [17]; analytics included in the learning dashboard, [22]; and learning curves, [2]).

The connection between LOs and questions, skill, is essential. In theory, an ideal question would be one that all students get wrong, but the feedback clarifies all students' misconceptions of the world, and therefore leads to all students mastering the skill. A teacher looking only at the result of that question with $100 \%$ failures would be horrified and might even replace it. The important thing here is not that students answered wrong, but rather what they learned by answering wrong and reading the feedback. This can be challenging to detect, but behind the scenes of the OLI environment there is a machine learning component [2] that can detect this and predict 
the likelihood of the student mastering a skill, which is available for students and teachers.

\subsection{Course Description}

The course in question for this study is the Programming Foundations (PF) module in the Software Development Academy (SDA). The SDA was developed as a result of the 2015 crisis for large parts of Europe when trying to handle the migrant effects of the Syrian war. The purpose was to quickly educate migrants for the IT job market where there was a substantial shortage of skilled personnel

The participants go through an application process where they are tested for logic, mathematical ability, problem solving and English. Selected applicants are then interviewed and $\approx 35$ are finally admitted to the program. SDA is an accelerated learning course over 15 full time weeks where the participants learn the basics of programming (in the PF module), software engineering, enterprise technologies [10], web development and group work using the Scrum methodology and team tools like GitHub. During this period, the participants are matched towards the job market, with a success rate of over $80 \%$ within 5 months of the completing the programme, despite having been unemployed for several years before starting the programme, and having unsuccessfully applied for a minimum of 100 jobs [33].

The PF module includes an introduction to object-oriented programming in Java and is equivalent to a full semester campus course at quarter speed (where full time is four parallel courses). PF evolved from the earlier iterations (SDA 1-5) that followed a traditional format: students received daily lectures and complated lab assignments before sitting an end of module exam. In SDA $6+7$, the traditional approach was replaced with a question-based learning approach. Students worked daily on online material interspersed with questions on the OLI platform, and then teachers rounded off the day with a discussion of the issues that emerged from the platform participation, i.e. focusing on the questions that caused the most difficulty and a general discussion of the topic of that day.

\section{METHOD}

There are a total of four non-overlapping student groups involved in this study, SDA 4-7. These are subdivided into the control group $($ SDA $4+5)$ and the experimental group (SDA $6+7)$. Depending on the data available from each group (see Table 1), we have compared the outcomes based on various combinations of these groups.

The students of SDA 5 were asked to volunteer a simple anonymous time log over the time spent on the SDA course. Due to administrative challenges, these time logs were only used for the last 10 days during the PF module (including the weekend). This time log was recorded on paper. An identical time log was used for the SDA 6 students for the entire PF module, but administered as an anonymous weekly web questionnaire.

Each instance of SDA included an evaluation process every week that investigated the students' experience, knowledge and confidence [11]. The experience component gave the students the chance to reflect on how the programme was going from their perspective, using a mixture of Likert-style items and open responses. The purpose of the knowledge quiz component was to test the knowledge of students on the material they had encountered during the week. The format was a multiple-choice quiz and students had 20 minutes to complete the assessment under exam conditions. These quizzes have had 57 identical questions since SDA 4, with four new questions added for SDA 5 and forward, which makes it possible to compare the learning outcomes between different instances.

Besides the quizzes, the participants also answered questions on their confidence of their knowledge of the material each week in a confidence survey. Students were presented with a list of typically 10 topics that had been encountered that week, and asked to give their level of agreement from very uncertain to very confident on a five-point scale. This was distributed on Fridays, covering the topics for the week, but the same survey was also distributed a week later to see how the confidence was affected by the continued work. This resulted in a total of five surveys: one for each week, plus the repeated week $1+2$ surveys distributed during week 2 and 3. Since SDA continued with another theme immediately after the $\mathrm{PF}$ module, we distributed the confidence survey for week 3 only once.

Two teachers were involved in the delivery, both also teaching the previous control installments of SDA. The teachers were interviewed separately regarding their experience of the differences between teaching with the digital QBL material and without. The interviews lasted 30 minutes and were recorded. Relevant parts were transcribed.

We also digitally asked the Teaching Assistants (TAs) who were involved in both SDA 5 and 6 to compare their experience between pre- and post-QBL.

The timelogs for these two teachers during the course are available for both the previous instances and the instances after our intervention.

Besides the educational data in Table 1, we also have timelogs from the development of the QBL material. While of less pedagogical interest, these timelogs were summarized to get an estimate for the costs for developing a course from scratch with question-based learning methodology.

\section{RESULTS}

\subsection{Learning Time}

Out of the 36 SDA 5 students, 24 volunteered time logs (67\%) for lessons 7-12 (the last half of the course). The 35 SDA 6 students volunteered 24 time logs for the first week (69\%), 19 for the 2nd week (54\%) and 14 for the 3rd week (40\%).

For the last half of the course (lessons 7-12) the SDA 5 students spent on average 69 hours in total, while SDA 6 students spent 72 hours on the same material. This difference is not statistically significant. Looking weekly, the SDA 6 students spent on average 44, 47 and 42 hours, including the two weekends.

\subsection{Results on Quizzes}

We combine SDA $6+7$ (QBL groups) and compare the total results of the quizzes with SDA $4+5$ (control group). Looking at the 57 questions, the QBL group had an average score (one point per question) of 34.7 and the control group 37.1, which looks like the QBL group (or the students) performed worse. However, a Welch Two Sample t-test gives a p-value of 0.10 , so the difference is not significant. 
Table 1: Summary of data collected for the study.

\begin{tabular}{|c|c|c|c|c|}
\hline & SDA 4 & SDA 5 & SDA 6 & SDA 7 \\
\hline Delivery Method & Traditional & Traditional & Question-based learning & Question-based learning \\
\hline Course Length (days) & 23 & 23 & 17 & 17 \\
\hline Student Time Logs & No & Yes, for the last 10 days & Yes & No (Covid) \\
\hline Student Experience Survey & Yes & Yes & Yes & Yes \\
\hline Student Knowledge Quiz & Yes, 57 questions & Yes, 61 questions & Yes, 61 questions & Yes, 61 questions \\
\hline Student Confidence Survey & Yes & Yes & Yes & Yes \\
\hline Teachers Involved & $A+B$ & $A+B$ & $A+B$ & $A+B$ \\
\hline Teachers Time Report & Yes & Yes & Yes & Yes \\
\hline
\end{tabular}

Comparing SDA $6+7$ with SDA 5 with all 61 questions, the mean values are identical at 37.5 , so the difference in the mean values above is due to an exceptionally good performance of the students in SDA 4.

\subsection{Results on confidence surveys}

When comparing the answers of the confidence surveys between SDA $4+5$ and SDA $6+7$, we cannot find any statistically significant differences.

\subsection{Teachers' Impressions}

The two teachers addressed the lecture preparations completely differently. Both teachers used the learning data from the teacher's dashboard to identify talking points for the lecture. However, whilst one teacher reduced the amount of preparation to making short notes (see Fig. 1) as a reminder not to forget anything that seemed important, the other teacher increased the time to prepare for all the what-ifs that might come when they no longer had a script to follow.

» Previously, I have felt much more tied to a script. ... [the advantage is] Then you know, you will ONLY talk about the things in the script. Now I must be prepared for a much wider area [as you do not know what the students will ask].

During lectures, both teachers report that the lecture became student-driven and much more interactive than previous years. Demonstrations became more ad-hoc, as they were derived directly from the students' questions. Even when asked if they wanted a break, the students preferred asking questions and the teachers interpreted this as a sign of motivation.

» The lecture became an exploration of the topics driven by how students had performed in the questions.

» The [learning dashboard in the] system itself directed you to exactly the point of difficulty.

»It is an awesome feeling when you realize how the students are improving their knowledge iteratively.

» In SDA 5 and earlier, there were always questions asked, but it tended to be particular [students], the stronger voices, [who asked them] ....now questions came from all over the room... and there were more questions in general.

Both teachers report that after the lectures they were more tired compared to previous years, but also more satisfied with the lectures and convinced that these lectures were more efficient for the students.
» We have stayed on track much better, when it comes to topics.
» Now I think: next year I will ask these ques- tions, rather than [as previously]: next year I will say these things. Focus has been moved to asking good questions, from having good things to say.
» I would like to do all my courses with QBL, I will not go back to traditional lectures.

Only one of the TAs answered but he confirms a sense that the online material supported a focus on the important issues for the course:

\footnotetext{
» I would say that the questions in the beginning of SDA 5 was more about BlueJ and how similar editor softwares worked and what were the pros and cons of a specific editor. I remembered that questions were not so much concepts in Object-oriented programming until later. In SDA 6, much of the questions were about programming concepts presented in OLI
} 


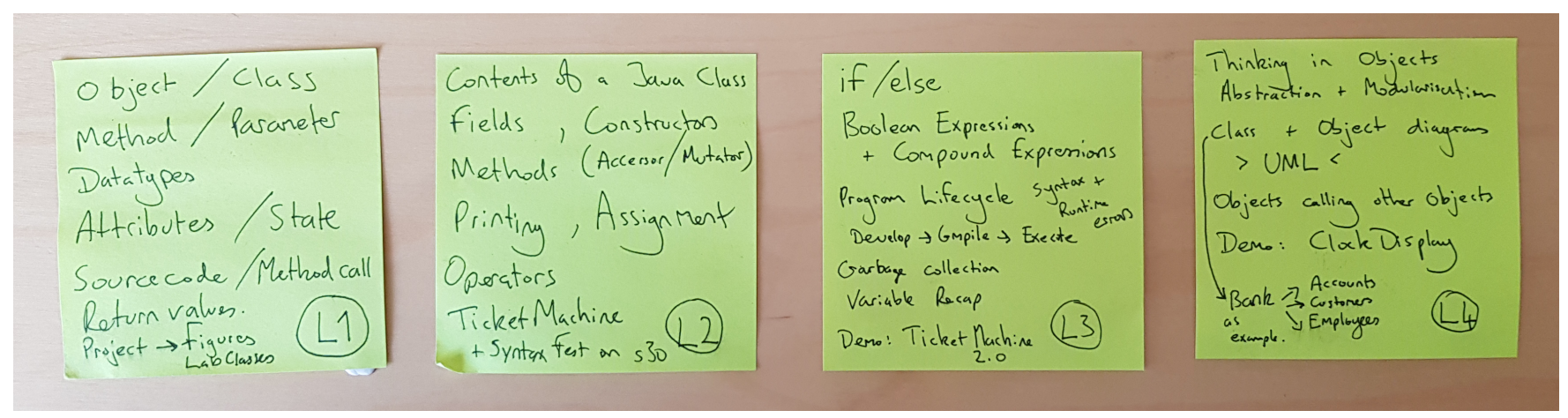

Figure 1: Teacher's minimal lecture notes for the first four lectures.

\subsection{Teaching Time}

The TAs' teaching time is directly proportional to the number of days, which resulted in a reduction from a total of 240 contact hours to 180 . For the teachers, the teaching time was reduced the same way from 40 to $30 \mathrm{hrs}$. When it comes to the preparation time it varies between SDA 6 (the first instance after the intervention) and SDA 7. In SDA 6 the preparation time was proportional to the previous instances $\approx 20 \mathrm{hrs}$, but in SDA 7 it dropped dramatically to $7.5 \mathrm{hrs}$. This means that the total teacher time was reduced from $60 \mathrm{hrs}$ to $37.5 \mathrm{hrs}$.

\subsection{Development Time}

The TAs spent a total of 305 hours developing and implementing. During the development of learning material for all of the topics of the course and the creation of formative questions, six meetings were held by the course responsible teacher with the TAs. These meetings and other course development related work added up to 37 hours for the course responsible teacher.

\section{DISCUSSION}

Despite the 25\% reduction in delivery days, we could not detect any differences in the students' time logs when it comes to time studied per delivery day, resulting in a reduction in total learning time. At the same time, results on the weekly quizzes and the confidence surveys were unaffected. However, the students' time logs should have been collected in a more consistent way. When SDA 4 was running we did not know that we would be able to use QBL in the future for this course at all. This became clear first when SDA 5 had already started. Hence, we collected the data we could, as soon as we could. In SDA 6 we should have continued with paper questionnaires, both for consistency and response frequency. We planned for this in SDA 7, but then the pandemic struck. It is always possible that self-reported time from the students does not reflect the actual time spent on the course. However, there is a limit for how much time that can be spent studying each day, and the collceted time logs are in line with the ones in [23], so we are fairly convinced that any differences are small. As the interviewed teachers stated: the online material kept the contact time more focused. Another explanation may be the increased student engagement reported in previous studies $[18,19]$.
The two teachers' different perspectives of preparations (more or less) can possibly be attributed to their personalities. One is comfortable improvising, whilst the other relies on carefully prepared material. This confirms results from previous research that learning dashboards influence teachers' pedagogical actions [25]. Despite this difference in attitudes towards preparation, both teachers were convinced that the QBL approach was an improvement over previous years, partly because the questions in the online learning material helped the learners to stay focused on the important topics, which is also confirmed by the TA.

Teaching preparation time is something you would expect to be reduced between course instances, and increase when you change something. In this case, the teaching preparation time did not increase with the switch to QBL (and it had been stable over the previous course iterations), but the drop to almost one third between the first and second QBL instance was dramatic.

The possibility of reducing learning time for the students with the same learning outcomes (in this case the scores on the quizzes) can be used in several different ways. For students, you could either ease the burden (so they can perform better in other courses or improve other abilities) or go in the opposite direction and increase the amount of learning objectives (either go deeper into subjects or cover more ground).

The PF module in SDA is more or less identical to a 7.5 ECTS credits course, but the students are far from average university students. They are highly motivated and bright individuals so it is not clear how the results would translate into regular intro courses. We will therefore pursue a study with the 180 students of the Computer Science program with the same online material, but this study on 35 students was necessary to do first.

The development time for this online course material, corresponding to 7.5 ECTS credits totals to 305 TA person hours and 37 teacher person hours. This should be put into relation to the time savings during course instances where 60 TA hours and 22.5 teacher hours will be saved in each instance. That is, the return on investment is roughly five course instances for the TAs and two for the teachers. The TAs were students at the Computer Science program, so we can view them as computer and Java experts, but the development environment and the methodology was new. 
There were lecture slides available and a structure for the course, but no formative questions. These formative questions with feedback are very time consuming to construct, and we did not reach the target of a minimum of eight questions per skill [2], but we are working on time saving solutions for that [9]. It should be noted that the SDA instances have only around 35 students, and the return on investment would likely be more significant in a larger course, as noted by House et al. (2018).

\section{CONCLUSION}

We have performed a study investigating the effectiveness of digitally supported question-based learning using Carnegie Mellon's Echo environment with OLI support. The study was similar to the CMU study [23] that reduced learning time by $50 \%$ whilst sustaining the same level of results. However, we did this in a tuition free environment, with newly developed and untested learning material, with a $25 \%$ reduction in learning time.

The outcomes were positive. Learning outcomes were unaffected by reduction of delivery time and learning time, and students spent their learning time in proportion to the delivery time. The return on investment in our case was six course instances for TAs and two for the teachers, despite this being a small group of students $(\approx 35)$.

\section{ACKNOWLEDGMENTS}

The Software Development Academy (SDA) was founded by Mattias Wiggberg (PI, KTH Royal Institute of Technology), Philipp Haller (KTH Royal Institute of Technology) and Farzad Golchin (Novare Potential). SDA is funded by the private fund Marianne och Marcus Wallenberg stiftelsen, by European Social Fund (ESF) and KTH Royal Institute of Technology. The authors want to thank all of the SDA team members, regular staff and part time students, and other colleagues devoted to make the project happen.

\section{REFERENCES}

[1] Susan A Ambrose, Michael W Bridges, Michele DiPietro, Marsha C Lovett, and Marie K Norman. 2010. How learning works: Seven research-based principles for smart teaching. John Wiley \& Sons.

[2] Olle Bälter, Dawn Zimmaro, and Candace Thille. 2018. Estimating the minimum number of opportunities needed for all students to achieve predicted mastery. Smart Learning Environments 5, 1 (2018), 15.

[3] Jon Baron. 2013. Randomized controlled trials commissioned by the Institute of Education Sciences since 2002: How many found positive versus weak or no effects. Washington, DC: Coalition for Evidence-Based Policy (2013).

[4] William G Bowen, Matthew M Chingos, Kelly A Lack, and Thomas I Nygren. 2014 Interactive learning online at public universities: Evidence from a six-campus randomized trial. Fournal of Policy Analysis and Management 33, 1 (2014), 94-111.

[5] Igor Chirikov, Tatiana Semenova, Natalia Maloshonok, Eric Bettinger, and René $\mathrm{F}$ Kizilcec. 2020. Online education platforms scale college STEM instruction with equivalent learning outcomes at lower cost. Science Advances 6, 15 (2020), eaay5324.

[6] Louis Deslauriers, Logan S McCarty, Kelly Miller, Kristina Callaghan, and Greg Kestin. 2019. Measuring actual learning versus feeling of learning in response to being actively engaged in the classroom. Proceedings of the National Academy of Sciences 116, 39 (2019), 19251-19257.

[7] Mark Dynarski, Roberto Agodini, Sheila Heaviside, Timothy Novak, Nancy Carey, Larissa Campuzano, Barbara Means, Robert Murphy, William Penuel, Hal Javitz, et al. 2007. Effectiveness of reading and mathematics software products: Findings from the first student cohort. (2007).

[8] The Racoon Gang. 2019 (accessed August 25, 2020). How much does it cost to develop an online course? https://raccoongang.com/blog/how-much-does-itcost-create-online-course

[9] Richard Glassey and Olle Bälter. 2020. Put the students to work: generating questions with constructive feedback. In IEEE Frontiers in Education Conference (FIE). IEEE.
[10] Richard Glassey, Olle Bälter, Philipp Haller, and Mattias Wiggberg. 2020. Addressing the Double Challenge of Learning and Teaching Enterprise Technologies through Peer Teaching. In 2010 IEEE/ACM 42nd International Conference on Software Engineering: Software Engineering Education and Training (ICSE-SEET). IEEE.

[11] Richard Glassey, Mattias Wiggberg, and Philipp Haller. 2018. Agile and Adaptive Learning via the ECK-model in the Software Development Academy. In EC-TEL Practitioner: 13th European Conference On Technology Enhanced Learning, EC-TEL.

[12] Rebecca Griffiths, Matthew Chingos, Christine Mulhern, and Richard Spies. 2014. Interactive online learning on campus: Testing MOOCs and other platforms in hybrid formats in the University System of Maryland. Ithaka $S+R 10$ (2014).

[13] Ann House, Jared Boyce, Sam Wang, Barbara Means, Vanessa Peters Hinton, and Tallie Wetzel. 2018. Next Generation Courseware Challenge Evaluation. Online Submission (2018).

[14] Ioana Jivet, Maren Scheffel, Hendrik Drachsler, and Marcus Specht. 2017. Awareness is not enough: pitfalls of learning analytics dashboards in the educational practice. In European Conference on Technology Enhanced Learning. Springer, 82-96.

[15] Pernilla Josefsson, Alexander Baltatzis, Olle Bälter, Fredrik Enoksson, Björn Hedin, and Emma Riese. 2018. Drivers and barriers for promoting technologyenhanced learning in higher education. In 12th International Technology, Education and Development Conference (INTED), MAR 05-07, 2018, Valencia, SPAIN. 45764584.

[16] Kenneth R Koedinger, Julie L Booth, and David Klahr. 2013. Instructional complexity and the science to constrain it. Science 342, 6161 (2013), 935-937.

[17] Kenneth R Koedinger, Albert T Corbett, and Charles Perfetti. 2012. The Knowledge-Learning-Instruction framework: Bridging the science-practice chasm to enhance robust student learning. Cognitive science 36, 5 (2012), 757-798.

[18] Kenneth R Koedinger, Jihee Kim, Julianna Zhuxin Jia, Elizabeth A McLaughlin, and Norman L Bier. 2015. Learning is not a spectator sport: Doing is better than watching for learning from a MOOC. In Proceedings of the second (2015) ACM conference on learning@scale.111-120.

[19] Kenneth R Koedinger, Elizabeth A McLaughlin, Julianna Zhuxin Jia, and Norman L Bier. 2016. Is the doer effect a causal relationship? How can we tell and why it's important. In Proceedings of the Sixth International Conference on Learning Analytics \& Knowledge. 388-397.

[20] E Lammers, A Bryant, Newman, and T Miles. 2015. Time for class: Lessons for the future of digital courseware in higher education. (2015).

[21] E Lammers, G Bryant, LS Michel, and J Seaman. 2017. Time for class: Lessons for the future of digital courseware in higher education - updated. (2017).

[22] Marsha Lovett. 2012. Cognitively informed analytics to improve teaching and learning. Presentation at EDUCAUSE Sprint. Retrieved October 5 (2012).

[23] Marsha Lovett, Oded Meyer, and Candace Thille. 2008. The Open Learning Initiative: Measuring the Effectiveness of the OLI Statistics Course in Accelerating Student Learning. Fournal of Interactive Media in Education (2008).

[24] Barbara Means, Yukie Toyama, Robert Murphy, Marianne Bakia, and Karla Jones. 2009. Evaluation of evidence-based practices in online learning: A meta-analysis and review of online learning studies. US Department of Education (2009).

[25] Inge Molenaar and Carolien Knoop-van Campen. 2017. Teacher dashboards in practice: Usage and impact. In European Conference on Technology Enhanced Learning. Springer, $125-138$.

[26] Sarah Ryan, Julia Kaufman, Joel Greenhouse, Ruicong She, and Judy Shi. 2016. The effectiveness of blended online learning courses at the community college level. Community College fournal of Research and Practice 40, 4 (2016), 285-298.

[27] Marcel Schmitz, Evelien Van Limbeek, Wolfgang Greller, Peter Sloep, and Hendrik Drachsler. 2017. Opportunities and challenges in using learning analytics in learning design. In European Conference on Technology Enhanced Learning. Springer, 209-223.

[28] Christian D Schunn and M Patchan. 2009. An evaluation of accelerated learning in the CMU Open Learning Initiative course Logic \& Proofs. Report, Learning Research and Development Center, University of Pittsburgh (2009).

[29] Paul S Steif and Anna Dollár. 2009. Study of usage patterns and learning gains in a web-based interactive static course. Fournal of Engineering Education 98, 4 (2009), 321-333.

[30] Candace Thille and Joel Smith. 2011. Cold Rolled Steel and Knowledge: What Can Higher Education Learn About Productivity? Change: The Magazine of Higher Learning 43, 2 (2011), 21-27.

[31] Anne Thoring, Dominik Rudolph, and Raimund Vogl. 2017. Digitalization of higher education from a student's point of view. EUNIS 2017-Shaping the Digital Future of Universities (2017), 279-288.

[32] Arto Vihavainen, Jonne Airaksinen, and Christopher Watson. 2014. A systematic review of approaches for teaching introductory programming and their influence on success. In Tenth annual conference on International computing education research. ACM, 19-26.

[33] Mattias Wiggberg, Elina Gobena, Matti Kaulio, Richard Glassey, Olle Bälter, Dena Hussain, and Philipp Haller. 2020. Toward an effective approach for re-skilling at universities: The case of KTH's Software Development Academy. Technical Report. KTH Royal Institute of Technology. 